\title{
Carga microbiana presente em jalecos de profissionais de saúde
}

\author{
Microbian charge presents in health professional's coat
}

Carga microbian presente en batas de profesionales de salud

Esther Nicoli Modesto ${ }^{1 *}$, José Nicolau Martins Ferreira ${ }^{1}$.

\section{RESUMO}

Objetivo: Levantar os riscos do uso indevido de jalecos por profissionais da saúde, através de uma revisão bibliográfica. Método: Revisão bibliográfica embasada em 14 artigos científicos publicados nas línguas inglesa e portuguesa, a partir do ano 2000 nas bases de dados: PubMed, LILACS, SciELO e BIREME. Resultados: Os microrganismos podem sobreviver de 10 a 98 dias em um jaleco. Estudos revelaram que o Staphylococcus aureus foi o patógeno mais isolado, sendo este com alta frequência de resistência a penicilina, eritromicina e clindamicina. Ocorreu ainda a presença de outros bacilos Gram positivos e bacilos Gram negativos em menor número, contudo, potencialmente infecciosos. Conclusão: É preciso o controle das doenças e agravos à saúde, bem como desses fatores condicionantes e determinantes, e com isso, do correto uso do uniforme de serviço em instituições de saúde.

Palavras-chave: Jaleco, Ambiente extra-hospitalar, Segurança.

\begin{abstract}
Objectives: Bring up the risk of the inappropriate use of coats by health professionals, through a bibliographic revision. Method: Bibliographic Revision based on 14 (fourteen) scientific articles published in English and Portuguese language from the year of 2000 in the data bases of: PubMed, LILACS, SciELO and BIREME. Results: The microorganisms can surviver from 10 to 98 days in a coat. Studies revealed that the Staphylococcus aureus was the most frequently isolated pathogen, being this one with a high frequency of resistance to penicillin, erythromycin, and clindamycin. There was also the presence of other Gram positive and Gram negative in less number however, potentially infectious. Conclusion: It is necessary to control diseases and injuries, as well as those conditioning and determinants factors, and with it, the correct use of uniforms in health institutions.
\end{abstract}

Keywords: Coat, Extra-hospital ambient, Safety.

\section{RESUMEN}

Objetivo: Levantar los riesgos del uso indebido de batas por profesionales de la salud, através de una revisión bibliográfica. Método: Una revisión de la literatura basada en 14 trabajos científicos publicados en los idiomas inglés y portugués, desde 2000, en la base de datos PubMed, LILACS, SciELO y BIREME. Resultados: Los microorganismos pueden sobrevivir de 10 a 98 días en una bata. Los estudios revelaron que el Staphylococcus aureus fue el patógeno más aislado, siendo éste con alta frecuencia de resistencia a la penicilina, eritromicina y clindamicina. Se observó la presencia de otros bacilos Gram positivos y bacilos Gram negativos en menor número, pero potencialmente infecciosos. Conclusión: Es necesario el control de las enfermedades y agravios a la salud, así como de esos factores condicionantes y determinantes, y con ello, del correcto uso del uniforme de servicio en instituciones de salud.

Palavras-clave: Batas, Ambiente extra hospitalario, Seguridad.

${ }^{1}$ Universidade Federal de Uberlândia-MG. * E-mail: esther-mn@hotmail.com 


\section{INTRODUÇÃO}

As infecções relacionadas à assistência à saúde (IRAS) atingem frequentemente as instituições de saúde, constituindo um grave problema de saúde pública mundial, elevando não só os custos hospitalares, mas também os índices de morbidade e mortalidade entre os clientes (FREIRE ILS, et al., 2013).

O controle das IRAS e a redução da disseminação de microrganismos resistentes são grandes desafios nas instituições de saúde. A principal via de transmissão desses microrganismos ocorre através das mãos dos profissionais de saúde em contato com os clientes (OLIVEIRA AC e SILVA MDM, 2013). Outro potencial reservatório de microrganismos, não menos importante, são os jalecos utilizados pelos profissionais de saúde em geral. Esse Equipamento de Proteção Individual (EPI), que tem função primordial de proteger 0 profissional, se contaminado, pode tornar-se veículo de disseminação de microrganismos sensíveis e resistentes. O homem, nas infecções cruzadas, é o responsável pela disseminação de microrganismos (agentes passivos), e deverá ser o enfoque das ações para controle da propagação de patógenos. A correta utilização de EPIs implica em melhoria da qualidade assistencial, redução de custos e infecções cruzadas oriundas de práticas de saúde hospitalares e ambulatoriais, tanto para os trabalhadores quanto para a comunidade atendida (CARVALHO CMRS, et al., 2009).

Segundo Carvalho CMRS et al. (2009), estudos realizados demonstraram que as roupas são uma importante via de transmissão de infecção no ambiente hospitalar. O jaleco do profissional, que entra em contato com líquidos e secreções do cliente, torna-se um verdadeiro disseminador de microrganismos. Através dessas vestimentas, bactérias multirresistentes, potenciais agentes de patologias como faringites, otites, pneumonia, tuberculose e até mesmo casos de óbito, são transportadas para locais públicos, e desses para unidades de saúde. Tantas vezes, a seriedade do fato é negligenciada por arrogância dos profissionais e até mesmo conhecimento insuficiente de princípios microbiológicos (CARVALHO CMRS, et al., 2009).

A presença de microrganismos como Staphylococcus aureus resistente à meticilina, Enterococcus sp resistentes a vancomicina, Acinetobacter baumannii, Klebsiella pneumoniae, Stenotrophomonas maltophilia e Serratia rubidae em jalecos já foi relatada e sugere riscos de disseminação de microrganismos nos ambientes hospitalares e extra-hospitalares. (OLIVEIRA AC e SILVA MDM, 2013; GASPARD P, et al., 2009).

Já existem projetos de lei em vigor em alguns estados brasileiros que proíbe o uso de jalecos e aventais fora do ambiente de trabalho. No estado de São Paulo, a Lei no 14.466, de 8/6/2011 é a lei responsável em punir aqueles que mesmo em consciência dos riscos que colocam à população, continuam fazendo o uso dessa vestimenta fora do ambiente hospitalar (BRASIL, 2011). Levando-se em consideração o risco biológico oferecido por esse EPI quando não utilizado em circunstâncias adequadas, foram estabelecidas ainda multas para o infrator.

Apesar da Norma Reguladora N-32 da Agência Nacional de Vigilância Sanitária, que restringe o uso do jaleco fora do local de trabalho, ainda é comum o descumprimento dessa regra entre os profissionais de saúde. Locais como restaurantes e lanchonetes próximos a instituições de saúde e em transportes coletivos, observa-se diariamente, diversos profissionais paramentados com seus aventais de mangas compridas, gravatas e estetoscópios nos pescoços, e até mesmo vestimentas específicas para área cirúrgicas, em locais públicos. O objetivo do artigo é levantar os riscos do uso indevido desse EPI, assim como os principais patógenos isolados, através de uma revisão bibliográfica.

\section{MÉTODOS}

Trata-se de uma pesquisa bibliográfica, de natureza qualitativa, com metodologia baseada na revisão de literatura. Para isso, foram utilizados 14 artigos científicos publicados nas línguas inglesa e portuguesa, a partir do ano 2000 nas bases de dados: PubMed, LILACS, SciELO e BIREME. As palavras chaves utilizadas foram "jaleco", "ambiente extra-hospitalar" e "segurança". A pesquisa por periódicos ocorreu entre os meses de junho e setembro de 2018. Foram incluídos artigos escritos em português e inglês, publicados a partir de 1991, e excluídos os publicados em outros idiomas, e com data anterior a esta. 


\section{RESULTADOS E DISCUSSÃO}

De acordo com a literatura embasada, foram realizadas pesquisas com diversos jalecos de profissionais de saúde que trabalham em áreas distintas. Após análise, todos eles foram considerados contaminados, (LOH E e HOLTON J, 2000).

Foi demonstrado que esses microrganismos podem sobreviver de 10 a 98 dias na vestimenta, que é confeccionada a partir de tecidos como algodão e poliéster. Essa seria uma fonte importante de disseminação de infecção hospitalar, mesmo que se apresentasse aparentemente limpo e sem manchas. (BANU A, et al., 2012).

O estudo de Banu A et al. (2012), revelou que o Staphylococcus aureus foi o patógeno mais isolado $(64,7 \%)$, resultado semelhante ao encontrado no estudo de Muhadi SA et al. (2007), Treakle AM et al. (2009), e Wong D et al. (1991), e diferente dos resultados revelados pelo estudo de Uneke CJ e ljeoma PA (2010), em que foram outros bacilos Gram positivos os mais comuns, quando isolados.

O Staphylococcus aureus pode provocar, por exemplo, infecções de pele, pneumonia, endocardite e osteomielite. $\mathrm{O}$ antimicrobiano padrão de suscetibilidade do cocos Gram positivos revelou que a maioria deles eram resistentes à Penicilina $(81,6 \%)$, Eritromicina $(70,6 \%)$ e Clindamicina $(58,7 \%)$ (ZACHARI KC, et al., 2001).

Tais dados consistem com a suscetibilidade padrão de organismos semelhantes aos isolados a partir de suspeita de infecções hospitalares no hospital em questão, o que indica possível ligação entre a contaminação dos jalecos e a transmissão de infecções aos pacientes suscetíveis. Ocorreu ainda a presença de bacilos Gram negativos em menor número, contudo, potencialmente infecciosos. (ZACHARI KC, et al., 2001).

O estudo de Freire ILS et al. (2012), destacou, por exemplo, que o gênero Enterobacter é oportunista e muito dificilmente causa alguma infecção primária, estando muito mais relacionada às infecções nosocomiais, principalmente de pacientes submetidos a procedimentos invasivos e à antibioticoterapia, além de possuir resistência a diversos antimicrobianos, desenvolvendo rápida resistência a novos agentes.

Segundo Morgan DJ et al. (2010) e Zachary KC et al (2001), 38,7\% das infecções hospitalares por Acinetobacter baumannii e Pseudomonas aeruginosa foram resultado de contaminação de luvas ou jalecos. Banu A et al. (2012), em seu artigo, descreveu uma pesquisa realizada em um hospital terciário em que a incidência de infecções hospitalares foi de 10\%, e o jaleco foi considerado a maior fômite dessas infecções. Nessa instituição, foram analisados jalecos de 100 estudantes, 65 do sexo masculino e 35 do sexo feminino. Dos 65 jalecos pertencentes a homens, 47 (74,3\%) estavam contaminados, enquanto dos 35 jalecos pertencentes a mulheres, $22(62,8 \%)$ estavam contaminados.

Isto estava em contraste com os resultados de um estudo que foi realizado por Muhadi AS et al. (2007), que encontrou no estudo que jalecos de mulheres tendiam a ser mais contaminados. Os estudantes que residiam em casas tendem a ter jalecos mais contaminados (72,9\%), enquanto aqueles que residiam em albergue tinham jalecos menos contaminados $(63,1 \%)$, o que é uma perspectiva preocupante, já que os microrganismos hospitalares foram propensos a se espalhar para a comunidade.

A maioria dos alunos (67\%) justificou fazer uso do jaleco em ambientes extra-hospitalares alegando parecer mais profissional, e $45 \%$ justificaram dizendo que esse era um símbolo do hospital. $O$ jaleco, na percepção do público, assim como o estetoscópio, é um símbolo da profissão médica (SALOOJEE H e STEENHOFF H, 2001).

Vestir esse uniforme é uma tradição, embora razões para o seu uso possam ter mudado. Embora os profissionais e alunos tivessem um alto nível de conscientização a respeito da contaminação da vestimenta, eles ainda o utilizavam em diferentes áreas da universidade, como a biblioteca, salas de leitura, cantina, salas de aula e até mesmo em instalações extra-hospitalares, em que seu uso não era necessário, resultado semelhante ao apresentado por Oliveira AC e Silva MDM (2013). 71\% dos alunos alegaram ter lavado seus uniformes a menos de 1 semana, mas apesar disso, a contaminação é elevada (62\%-78\%), independente do intervalo de tempo desde a última lavagem. 
Isto foi semelhante às descobertas de um estudo que foi realizado por Wong $D$ et al. (1991), que descobriu que as contagens microbianas não variam com o tempo do uso dos uniformes. Um estado estacionário máximo foi atingido na primeira semana de utilização dos jalecos, o que não se alterou significativamente em seguida.

O estudo de Loh E e Holton J (2000), realizado com 100 estudantes, apontou que não houve correlação entre o local que o aluno armazena seu jaleco e a carga microbiana predominante. A manga era o local mais suscetível de ser fortemente colonizado, seguido pelo bolso.

Como os profissionais ou estudantes em análise prestavam assistência direta ao paciente, a manga do revestimento, especialmente a braçadeira, é o sítio que mais frequentemente entra em contato com pacientes, por isso, existe o risco potencial para que os microrganismos sejam transferidos ou adquiridos a partir do doente. Por outro lado, transferência de microrganismos de mangas para as mãos (e vice-versa) é também possível. Este risco pode ser reduzido proporcionando aos alunos ou profissionais jalecos de mangas curtas, facilitando assim sua capacidade de lavar adequadamente as mãos e remover um fonte potencial de contaminação da manga (BANU A, et al., 2012).

Ainda no estudo de Banu A et al. (2012), 89 dos jalecos foram lavados em casa, enquanto 11 foram lavados em lavanderias, e o grau de contaminação foi o mesmo em ambos os conjuntos. O estudo de Carvalho CMRS et al. (2009) evidenciou que todos os componentes do processo de lavagem contribuem para remover ou matar os microrganismos. Levando-se em consideração a frequência de contato do profissional com pacientes, e a agenda lotada dos profissionais, é razoável esperar que os uniformes estejam contaminados por bactéria potencialmente patogênicas, o que foi demonstrado em diversos estudos. Muhadi SA et al (2007), mostrou em sua pesquisa que profissionais que lidam com a assistência direta ao paciente tendem a se preocupar com mais frequência a respeito da higiene de seu uniforme em relação aos que não trabalham com essa assistência direta, que não tem contato direto com o ambiente hospitalar. É importante destacar que, apesar de sujidades explícitas em uniformes de trabalhos, a maioria dos profissionais/estudantes apenas os lavava com intervalos de cerca de 1 mês (LOH E e HOLTON J, 2000).

Ainda segundo Banu A et al. (2012), uma série de estudos anteriores havia demonstrado que o cumprimento dos protocolos de higiene das mãos entre todos os profissionais de saúde, incluindo os médicos, era pobre. A falta de higiene das mãos, sem dúvidas, aumenta o grau de contaminação dos jalecos, uma vez que são frequentemente tocados pelos profissionais no exercício de suas atividades. Com isso, há uma necessidade premente de promover a lavagem escrupulosa das mãos antes e depois da assistência ao paciente. Um resultado semelhante foi abordado no estudo de Carvalho CMRS et al. (2009), que apontou a lavagem das mãos como um procedimento de baixo custo, relativamente simples, e de extrema importância na prevenção de infecções. Há poucas evidências de outros métodos melhores que a lavagem das mãos na prevenção de infecção hospitalar, independentemente do tipo de jaleco que o profissional de saúde esteja fazendo uso.

Gaspard P et al (2009), relata que em seu estudo que envolveu mais de 500 amostras, foi possível concluir que o uso de aventais de plástico (capotes plásticos) e a gestão de conteúdos de bolso melhorou a taxa de contaminação das vestimentas. Loh E e Holton J (2000), destaca que o plástico laminado e algodão impermeável apresentam baixa taxa de transferência bacteriana.

A utilização de jalecos durante atendimentos que envolvam contato com material biológico tornou-se uma prática obrigatória, imprescindível para a proteção do profissional. Contudo, a utilização indevida do EPI, como fora de unidades de saúde, pode tornar-se um risco para a saúde pública (CARVALHO CMRS, et al., 2009). Vestuário, uniformes, casacos de laboratório ou batas de isolamento utilizadas como equipamento de proteção individual (EPI) podem tornar-se contaminados por patógenos potenciais após a assistência direta de um paciente colonizado ou infectado por algum agente infeccioso. Embora o vestuário contaminado não tenha sido implicado na transmissão direta, existe o risco potencial das roupas "sujas" transferirem agentes infecciosos a pacientes suscetíveis. O tratamento adequado dos jalecos por médicos e outros profissionais 
da saúde poderia minimizar a infecção cruzada e contribuir para segurança do paciente além de, potencialmente reduzir infecções hospitalares (UNEKE CJ e IJEOMA PA, 2010).

\section{CONCLUSÃO}

Este estudo almejou identificar a relação do uso de jalecos em ambientes extra-hospitalares e a disseminação de bactérias multirresistentes, que podem vir a gerar cada vez mais resistência e, com isso, patologias graves. É preciso o controle dessas doenças e agravos à saúde, bem como desses fatores condicionantes e determinantes. Sendo assim, recomenda-se as medidas de controle e prevenção dos mesmos, que pode ser feita com a utilização desse EPI exclusivamente em ambiente de serviços de saúde, cumprindo a função designada para esse uniforme.

\section{REFERÊNCIAS}

1. BANU A, ANDAND M, NAGI N. White coats as a Vehicle for bacterial disseminations. Journal of Clinical and Diagnostic Research, 2012; 6(8): 1381-1384.

2. CARVALHO CMRS, MADEIRA MZA, TAPETY FI et al. Aspectos de Biossegurança Relacionados ao Uso do Jaleco Pelos Profissionais de Saúde: uma revisão de literatura. Texto E Contexto Enfermagem, Florianópolis, 2009; 18: 355-358.

3. FREIRE ILS, MENEZES LCC, SOUSA NML et al. Epidemiologia das infecções relacionadas à assistência à saúde em unidade de terapia intensiva pediátrica. Revista Brasileira de Ciências da Saúde, São Caetano do Sul, 2013; 11 (35): 10.

4. GASPARD P, ESCHBACH E, GUNTHER D et al. Meticillin-resistant Staphyococcus aureus contamination of healthcare workers' uniforms in long-term care facilites. J Hosp Infect, 2009; 71(2): 170-5.

5. LOH E, HOLTON J. Bacterial flora on the white coats of medical students. J Hosp Infect, 2000; 45(1): 65-8.

6. MORGAN DJ, STEPHEN Y, LIANG Y et al. Frequent multidrug-resistant Acinetobacter baumannii contamination of gloves, gowns, and hands of healthcare workers. Infect Control Hosp Epidemiol, 2010; 31(7):716-21.

7. MUHADI SA, AZNAMSHAH NA, JAHANFAR S. A cross sectional study on the microbial contamination of the medical student's white coats. Malayasian Journal of Microbiology, 2007; 3(1): 35-38.

8. OLIVEIRA AC, SILVA MDM. Caracterização epidemiológica dos microrganismos presentes em jalecos dos profissionais de saúde de um hospital geral. Revista Eletrônica de Enfermagem, Belo Horizonte, 2013; $15: 81$.

9. SALOOJEE H, STEENHOFF A. The health professional's role in preventing nosocomial infections. Postgrad Med J, 2001; 77(903):16-9.

10. SIEGEL JD, RHINEHART E, JACKSON M et al. The Healthcare Infection Control Practices Advisory Committee (HICPAC). Guideline for isolation precautions: preventing transmission of infectious agents in healthcare settings, 2007.

11. TREAKLE AM, THOM KA, FURANO JP et al. Bacterial contamination of health care workers' white coats. Am J Infect Control, 2009; 37(2):101-5.

12. UNEKE CJ, IJEOMA PA. The potential for nosocomial infection transmission of the white coats which were used by physicians in Nigeria: Implications for improved patient-safety initiatives. World Health and Population, 2010; 11(3): 44-54.

13. WONG D, NYE K, HOLLIS P. The microbial flora on doctor's white coats. British Med Journal, 1991; 303: 21-28. 14. ZACHARY KC, BAYNE PS, MARRISON VJ et al. Contamination of gowns, gloves, and stethoscopes with vancomycin resistant enterococci. Infect Control Hosp Epidemiol, 2001; 22(1): 560-4. 